\title{
NEW COMBINATION SUPPOSITORIES OF LORNOXICAM AND ALOIN FOR RHEUMATOID ARTHRITIS
}

\author{
ASHTI M H SAEED ${ }^{1}$, MARYAM H ALAAYEDI ${ }^{2}$, ATHMAR DH H ALSHOHANI ${ }^{1}$ \\ ${ }^{1}$ Department of Pharmaceutics, Mustansiriyah University, College of Pharmacy, Baghdad, Iraq. ${ }^{2}$ Department of Pharmaceutics, Kerbala \\ University, College of Pharmacy, Kerbala, Iraq. Email: phashti@gmail.com
}

Received: 05 October 2017, Revised and Accepted: 20 November 2017

\section{ABSTRACT}

Objective: The objective of our current work is to formulate, optimize and evaluate new combination rectal suppositories as a treatment for rheumatoid arthritis that contains both lornoxicam and aloin. Both are strong anti-inflammatory agents, and a combination of both may have synergistic effect as an anti-inflammatory treatment.

Methods: Rectal suppositories containing $8 \mathrm{mg}$ lornoxicam and $200 \mathrm{mg}$ aloin were formulated by heat fusion method. Different combinations of different molecular weights of polyethylene glycol (PEG) were used for the formulated suppositories. The formulated suppositories were evaluated for their visual appearance, weight variation, hardness, friability, disintegration time, melting temperature, and drug content uniformity.

Results: All the formulations prepared were within the required limits for USP. When the release study was performed, both drugs were released from all the formulations prepared. However, formulation F7 which is composed of PEG 400 30.88\% (w/w): PEG 4000 46.32\% (w/w) was superior to other formulations in which more than $80 \%$ of both drugs loaded were released after 35 min. The presence of both drugs in the same suppository did not affect their release.

Conclusion: A new combination suppositories have been obtained where the two combined drugs were released fast without interference with each other release. The proposed new combination has the potential to be used as a strong analgesic and anti-inflammatory treatment compared to using lornoxicam or aloin alone.

Keywords: Lornoxicam, Aloin, Rectal suppositories, Anti-inflammatory, Polyethylene glycol.

(C) 2018 The Authors. Published by Innovare Academic Sciences Pvt Ltd. This is an open access article under the CC BY license (http://creativecommons. org/licenses/by/4. 0/) DOI: http://dx.doi.org/10.22159/ajpcr.2018.v11i2.22921

\section{INTRODUCTION}

One of the most common autoimmune diseases in populations around the world is rheumatoid arthritis (RA). RA is characterized by inflammation of the synovial membrane lining the joints which result in pain, swelling, cartilage destruction, and eventually bone erosion. Patients with RA have a low quality of life due to their restricted movement and inability to function properly. It is estimated that the prevalence of RA in general population is $0.8 \%$ mostly at the age group $30-50$ years old [1-4]. There is no cure for RA, and the treatment is based on relieving the pain and symptoms of the disease to improve the quality of life for the patients. The available treatments in the clinic are based on the severity of the condition such as corticosteroids, nonsteroidal anti-inflammatory drugs (NSAIDs), and disease-modifying antirheumatic drugs; however, NSAID is commonly used especially at early stages of the disease $[5,6]$.

NSAID such as diclofenac sodium, naproxen, piroxicam, ketoprofen, and indomethacin is used to control and lower the pain and inflammation associated with the disease. Although NSAID is widely prescribed and used in the clinic, their use is compromised by their high risk of gastric side effects that ranges from simple nausea and abdominal discomfort to the probability of developing ulcer with long-term treatment [7-9]. There are several NSAID available in the clinic, and new generations are constantly developed to reduce the side effect and improve the potency of the old generations; for example, lornoxicam. The use of lornoxicam is increasing in the clinic due to its potent anti-inflammatory, analgesic, antipyretic, and lower incidence of side effect compared to other NSAIDs such as naproxen. Furthermore, the analgesic effect of lornoxicam and opioids is comparable $[10,11]$.

Recently, several plants have emerged as potential anti-inflammatory agents for anti-inflammatory diseases such as RA $[12,13]$. One of the promising plants is Aloe vera. Aloin vera has been traditionally used worldwide for centuries as a medicinal agent for the treatment of gastric diseases, skin conditions and wound healing [14-16]. On chemical analysis of the plant gel extract, more than 70 active biological ingredients were identified including aloin. Aloin is an anthraquinone glycoside that is currently used as a laxative and widely investigated for its pharmacological activity as anti-inflammatory, anticancer, and antibacterial properties $[17,18]$. Due to the chronic nature of the disease combination therapy is used to improve the efficacy of the treatment. The use of both lornoxicam and aloin will have the potential to improve the efficacy of the treatment.Another factor to be considered in the treatment of RA is the route of administration. Systemic administration through the gastrointestinal tract or injection is often associated with high risk of side effect [6]. To offer an alternative that is minimally invasive with a low incidence of side effects, high potency and rapid onset of action rectal route is preferred.

The aim of this work was to prepare and characterize a combination suppository of aloin and lornoxicam as potential combination treatment of RA. Different suppository bases will be investigated, and the suppositories will be characterized regarding their visual appearance, weight variation, melting point, drug content, and disintegration. In vitro release studies will also be performed.

\section{MATERIALS AND METHODS}

\section{Materials}

Lornoxicam (Wuhan, Senwayer, Century Chemical Co., Ltd., China), aloin extracted (Baoji, Guokang, Biotechnology Co., Ltd. Shanghai, China), polyethylene glycol (PEG) (400, 600, 1000, and 4000) (Sinopharm Chemical Reagents Co., Ltd, China), PEG 6000 (Yonghua Chemical Technology Co., Ltd, Jiangsu, China), Tween 80 (HiMedia Laboratories, Pvt. Ltd., Mumbai, India), and methylparaben and propylparaben (Interchimiques SA, France) were used. 
Preparation of lornoxicam-aloin suppositories

Heat fusion method was used for the preparation of combination suppositories. For the preparation of the suppositories, different grades of PEG $(400,600,1000,4000$, and 6000$)$ were used as a base. The total weight of each suppository was $2 \mathrm{~g}$ including $8 \mathrm{mg}$ of lornoxicam and $200 \mathrm{mg}$ of aloin. The composition of each formula is illustrated in Table 1. Melting method was used for the formulation of the suppositories. The base composition (PEG) was weighed and melted in a water bath at $65-70^{\circ} \mathrm{C}$. When the base was completely melted, the aloin and lornoxicam in powder form were incorporated followed by the addition of Tween 80 as an emulsifying agent with continuous stirring. When a homogenous mixture was visually observed the mixture was removed from the water bath and poured into $2 \mathrm{~g}$ suppository mold. The molds were placed in the fridge at $4^{\circ} \mathrm{C}$ to allow the melted base to harden and the formation of the suppository [19]

\section{UV method for drug quantification}

Analysis of aloin and lornoxicam by UV visible spectrophotometer (UV, 1650PC, Shimadzu, Japan) was performed. The detection wavelength of both drugs was previously recorded by scanning solutions of each drug separately using UV. For aloin, the detection wavelength was $266 \mathrm{~nm}$, and the correlation coefficient of the calibration curve was $\mathrm{R}^{2:} 0.999$ for a concentration range of $5-30 \mu \mathrm{g} / \mathrm{ml}$, indicating acceptable linearity. The samples for the calibration curve were made using phosphate saline buffer at pH 7.2 as a solvent. For lornoxicam, the detection wavelength was $375 \mathrm{~nm}$, and the correlation coefficient of the calibration curve was $\mathrm{R}^{2:} 0.9993$ for a concentration range of $2-20 \mu \mathrm{g} / \mathrm{ml}$, indicating acceptable linearity. The samples for the calibration curve were also made using phosphate saline buffer at pH 7.2 as a solvent.

\section{In vitro evaluation of suppositories}

The following tests were performed for the evaluation of the prepared suppositories.

\section{General appearance}

For each batch prepared, 20 suppositories were randomly selected for physical characterization which includes color and surface characteristics. Each suppository was longitudinally cut and inspected for deformities visually with the naked eye. The signs of physical deformity inspected were fissuring, exudation, fat blooming, and migration of the active ingredients. The length and width of each suppository were also measured, and the mean value was calculated.

\section{Weight variation}

The weight variation for each batch of suppositories was calculated. 20 suppositories of each batch were weighted individually, and the mean was calculated followed by calculation of the percent of deviation from the mean. No more than two suppositories should deviate by more than $5 \%$ of the average weight but should not deviate more than $7.5 \%$ [20].

\section{Hardness}

Hardness was measured using manual hardness tester (Vanguard, USA) for each batch of suppositories. From each batch three suppositories were randomly chosen and the average was calculated [21].

\section{Melting point determination}

The melting point for each suppository batch was evaluated. One suppository from each batch was placed in $5 \mathrm{ml}$ phosphate buffer $(\mathrm{pH} 7.2)$ and placed in a water bath at $37^{\circ} \mathrm{C}$. The temperature for the whole suppository melting was recorded when there were no fragments of the suppository to be observed [22].

\section{Liquefaction}

Liquefaction test indicates the time required for the suppository to liquefy under pressure similar to the rectal pressure in the presence of liquid at $37^{\circ} \mathrm{C}$. The test was performed using burette. The burette had a broad opening on one end and a narrow on the other. The burette was filled with $5 \mathrm{ml}$ phosphate buffer $\mathrm{pH} 7.2$ and placed in a water bath at $37^{\circ} \mathrm{C}$. For each batch a suppository was placed inside the burette from the broad end and pushed to the narrow end. A thin glass rod was placed on the top of the suppository and the time for the glass rod to penetrate the suppository was recorded as liquefaction time [23].

\section{Friability test}

Friability test (\% F) was conducted using friabilator (Vanguard USA) was used to study the friability of the prepared suppositories. From each batch, 20 suppositories were weighed and placed in the friabilator drum. The drum was rotated at $25 \mathrm{rpm}$ for $4 \mathrm{~min}$. The suppositories then removed and weighed. The percent of weight loss was calculated using the following equation [23]:

$\% \mathrm{~F}=$ Loss in weight/Initial weight $\times 100$

\section{Drug content uniformity}

For each batch prepared drug content test was performed. Each suppository tested was placed in $200 \mathrm{ml}$ phosphate buffer $\mathrm{pH} 7.2$ at $37^{\circ} \mathrm{C}$ and allowed to melt completely with stirring. After melting, $1 \mathrm{ml}$ sample was withdrawn from the mixture and completed to $100 \mathrm{ml}$ with phosphate buffer $\mathrm{pH} 7.2$ followed by filtration. UV spectrophotometry was used for determination of drug content [22].

\section{Disintegration test}

Disintegration test was performed for each batch using disintegration apparatus (Cooply, Nottingham, UK). Each suppository was placed in $900 \mathrm{ml}$ phosphate buffer $\mathrm{pH} 7.2$ at $37^{\circ} \mathrm{C}$ and the time required for the suppository to fragment and pass through the sieve was recorded and considered as the disintegration time [21].

\section{In vitro dissolution study}

The release of lornoxicam and aloin from different suppository formulations was studied using dissolution apparatus USP Type II (Paddle) (Pharma Test, 63512 Hainburg Germany). For each batch, a suppository was placed in $900 \mathrm{ml}$ phosphate buffer ( $\mathrm{pH} 7.2$, Temperature $37^{\circ} \mathrm{C}$ ) at a $100 \mathrm{rpm}$, and the conditions were maintained through the experiment. Aliquots of $5 \mathrm{ml}$ were collected at predetermined time intervals, filtered through $0.45 \mu \mathrm{m}$ filter and used for quantitative determination of aloin and lornoxicam using UV. Each sample was replaced with $5 \mathrm{ml}$ fresh buffer. The cumulative percentage of drug release was calculated and plotted versus time [24].

Table 1: The composition of different solid suppository formulations

\begin{tabular}{|c|c|c|c|c|c|c|c|c|c|c|}
\hline \multirow[t]{2}{*}{ Base $\%(w / w)$} & \multicolumn{10}{|c|}{ Formulation code } \\
\hline & F1 & F2 & F3 & F4 & F5 & F6 & F7 & F8 & F9 & F10 \\
\hline PEG 400 & - & - & 46.32 & 46.32 & 30.88 & - & 30.88 & - & - & - \\
\hline PEG 600 & - & - & - & - & - & - & - & - & - & - \\
\hline PEG 1000 & - & - & - & - & - & 30.88 & - & 46.32 & 46.32 & 30.88 \\
\hline PEG 4000 & 77.2 & - & 30.88 & - & - & - & 46.32 & & 30.88 & 46.32 \\
\hline PEG 6000 & - & 77.2 & - & 30.88 & 46.32 & 46.32 & - & 30.88 & - & - \\
\hline
\end{tabular}

*The final weight of each suppository is $2 \mathrm{~g}$ (each suppository contains $10 \%$ aloin, $0.4 \%$ lornoxicam, $10 \%$ Tween $80,1.4 \%$ methylparaben, and $1.4 \%$ (w/w)

propylparaben); PEG: polyethylene glycol 
Table 2: The hardness of different suppository formulations

\begin{tabular}{|c|c|c|c|c|c|c|c|c|c|c|}
\hline Formulation code & F1 & F2 & F3 & F4 & F5 & F6 & F7 & F8 & F9 & F10 \\
\hline Hardness $\left(\mathrm{kg} / \mathrm{cm}^{2}\right)$ & $3.1 \pm 0.2$ & $3.1 \pm 0.1$ & $2.4 \pm 0.1$ & $2.9 \pm 0.4$ & $3.9 \pm 0.1$ & $3.01 \pm 0.3$ & $2.8 \pm 0.2$ & $2.9 \pm 0.2$ & $2.8 \pm 0.1$ & $2.8 \pm 0.1$ \\
\hline Friability (\%) & $0.04 \pm 0.01$ & $0.06 \pm 0.02$ & $0.1 \pm 0.03$ & $0.04 \pm 0.04$ & $0.03 \pm 0.2$ & $0.03 \pm 0.01$ & $0.07 \pm 0.03$ & $0.1 \pm 0.01$ & $0.07 \pm 0.02$ & $0.08 \pm 0.04$ \\
\hline
\end{tabular}

\section{Data analysis}

All results are presented as the mean and standard deviation of three samples unless stated otherwise and data were plotted using one-way ANOVA (GraphPad Prism 7.00, USA).

\section{RESULTS AND DISCUSSION}

The treatment of RA in the clinic is mainly with the use of antiinflammatory drugs, in particular, NSAIDs [9]. The GI side effects associated with NSAIDs led to the search of alternative pathways for delivery. Rectal route offers the advantage of fewer side effects and ease of administration compared to other routes [25]. As previously described in the introduction, both lornoxicam and aloin have preferable properties compared to other anti-inflammatory drugs. Although lornoxicam and aloin were previously formulated as suppositories, up to our knowledge, no suppository formulation of aloin and lornoxicam combined together was previously reported [26-28]. Different suppository batches (F1 to F10) were formulated for the combined rectal delivery of aloin and lornoxicam in Table 1. After formulation, each batch was visually inspected for different physical characteristics and longitudinally cut for further inspection. All the prepared suppositories were yellowish green in color with smooth shiny surfaces, no cracking or fraction was observed. Smoothness of the surface is important to ensure ease of administration [29]. Uniformity of color indicates that proper mixing and lack of migration of the active ingredients. When longitudinally cut all the prepared formulations demonstrated no signs of pitting, fissuring, exudation, and fat blooming. All the prepared suppositories were uniform in length and width.

Mechanical strength is important parameter to be considered when formulating suppositories. Suppositories should withstand handling, insertion, packaging, and transportation without cracking [30]. The mechanical strength of the formulated suppositories can be estimated using hardness and friability tests. The hardness of the prepared suppositories was evaluated, and the results were demonstrated in Table 2. From the results, it was clear that all the prepared formulations were hard and able to withstand pressure higher than $2 \mathrm{~kg} / \mathrm{cm}^{2}$. The friability of the formulated suppositories was evaluated in Table 2 . The friability $\%$ of all the prepared formulas was within the required limits [20].

Weight variation for each batch was calculated according to US Pharmacopeia. All the suppositories prepared for each formulation were within the required limits of pharmacopeia in Table 3. Furthermore, drug content uniformity was evaluated for both lornoxicam and aloin according to pharmacopeia [20]. All the formulations tested met the required limits in which the drug content must be above $95 \%$ in Table 3.

The disintegration and melting temperature of the formulations were measured and compared to study the effect of the base used on both properties, and the results are demonstrated in Table 4. Formulations made with PEG 6000 demonstrated higher disintegration time and melting temperature compared to other formulations. When the PEG 6000 (F2) was completely replaced with PEG 4000 (F1), both disintegration time and melting temperature were reduced. The disintegration time was reduced from 9 to $8.2 \mathrm{~min}$, and the melting temperature was reduced from 54.6 to $51.4^{\circ} \mathrm{C}$. Similar behavior was observed when PEG 6000 was mixed in different proportions with PEG 400 (F4 and F5) and PEG 1000 (F6 and F8). It was noticed that when the ratio of PEG 6000 was high compared to PEG 400, the melting temperature and disintegration time were also high. Furthermore, replacing PEG 400 with PEG 1000 demonstrated also an increase in
Table 3: Drug content uniformity percent of both aloin and lornoxicam

\begin{tabular}{llll}
\hline \multirow{2}{*}{$\begin{array}{l}\text { Formulation } \\
\text { code }\end{array}$} & \multicolumn{2}{l}{ Drug content (\%) } & Average weight g \\
\cline { 2 - 3 } & Aloin & Lornoxicam & \\
\hline F1 & $95.01 \pm 1.5$ & $98.2 \pm 0.4$ & $2.15 \pm 0.3$ \\
F2 & $99 \pm 1.4$ & $97 \pm 0.3$ & $2.1 \pm 0.6$ \\
F3 & $100.9 \pm 0.8$ & $96.9 \pm 0.2$ & $2.13 \pm 0.7$ \\
F4 & $95.9 \pm 0.8$ & $95.9 \pm 0.2$ & $2.21 \pm 0.4$ \\
F5 & $95.8 \pm 0.6$ & $99.8 \pm 0.7$ & $1.99 \pm 0.5$ \\
F6 & $95.8 \pm 0.87$ & $95.7 \pm 0.1$ & $2.2 \pm 0.4$ \\
F7 & $95.12 \pm 0.45$ & $96.1 \pm 0.6$ & $2.15 \pm 0.2$ \\
F8 & $99.13 \pm 0.43$ & $99.13 \pm 0.22$ & $2.13 \pm 0.29$ \\
F9 & $96.9 \pm 0.3$ & $96.9 \pm 0.3$ & $2.2 \pm 0.8$ \\
F10 & $98.2 \pm 0.6$ & $98.2 \pm 0.5$ & $2.1 \pm 0.4$ \\
\hline
\end{tabular}

Table 4: Disintegration time and melting temperature for the suppositories formulated

\begin{tabular}{llll}
\hline $\begin{array}{l}\text { Formulation } \\
\text { code }\end{array}$ & $\begin{array}{l}\text { Disintegration } \\
\text { (min) }\end{array}$ & $\begin{array}{l}\text { Melting } \\
\text { temperature } \\
\left({ }^{\circ} \mathbf{C}\right)\end{array}$ & Friability (\%) \\
\hline F1 & $8.2 \pm 0.4$ & $51.4 \pm 1.8$ & $0.04 \pm 0.01$ \\
F2 & $9 \pm 0.3$ & $54.6 \pm 2.3$ & $0.06 \pm 0.02$ \\
F3 & $4.2 \pm 0.3$ & $33.8 \pm 1.04$ & $0.1 \pm 0.03$ \\
F4 & $6 \pm 0.7$ & $33.8 \pm 1.04$ & $0.04 \pm 0.04$ \\
F5 & $7 \pm 0.8$ & $36.3 \pm 0.2$ & $0.03 \pm 0.21$ \\
F6 & $7.8 \pm 0.6$ & $49.1 \pm 2.4$ & $0.03 \pm 0.01$ \\
F7 & $5.3 \pm 0.2$ & $36.9 \pm 1.1$ & $0.07 \pm 0.03$ \\
F8 & $8.5 \pm 0.3$ & $44.6 \pm 2.5$ & $0.1 \pm 0.003$ \\
F9 & $6.2 \pm 0.7$ & $42.3 \pm 0.6$ & $0.07 \pm 0.02$ \\
F10 & $6.7 \pm 0.4$ & $45.4 \pm 2.6$ & $0.08 \pm 0.04$ \\
\hline
\end{tabular}

melting points and disintegration time. The results are consistent with what was previously reported in the literature that when the molecular weight of PEG used increased, the disintegration time and melting temperature will also increase. The same behavior was observed when PEG 4000 was mixed with PEG 400 (F3 and F7) and PEG 1000 (F9 and F10).

\section{In vitro drug release}

Drug release from suppositories is affected by several factors such as type of base used, the compatibility between the drug and the base and the chemical nature of the additives used. If combination suppository was formulated there is also a possibility that the release of one drug will be compromised by the presence of another drug. For each batch formulated, the release of aloin and lornoxicam was studied. The release of aloin was compared for all the formulations prepared. After $10 \mathrm{~min}$ of the release around $40 \%$ of the drug-loaded was released from all the formulas. However, further into the release studies differences were observed between different formulations. Around $80 \%$ of the aloin was released from F9 to F7 after 35 min compared to around $65-70 \%$ for the other formulas (Fig. 1).

For lornoxicam, $50 \%$ of the drug was released from $\mathrm{F} 1$ to $\mathrm{F} 2$ after 10 min compared to around $40 \%$ for the other formulas. However, with the continuation of the release studies, there was a clear difference in release between the formulas. After $35 \mathrm{~min} 90 \%$ of lornoxicam was released from $\mathrm{F} 7$ compared to other formulas where the release range was $75-85 \%$ (Fig. 2). 


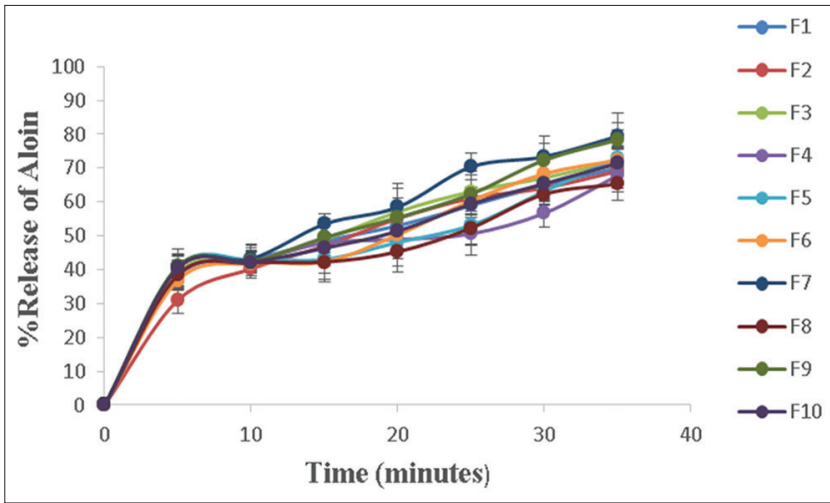

Fig. 1: Aloin release studies from different suppository formulations $(n=3)$

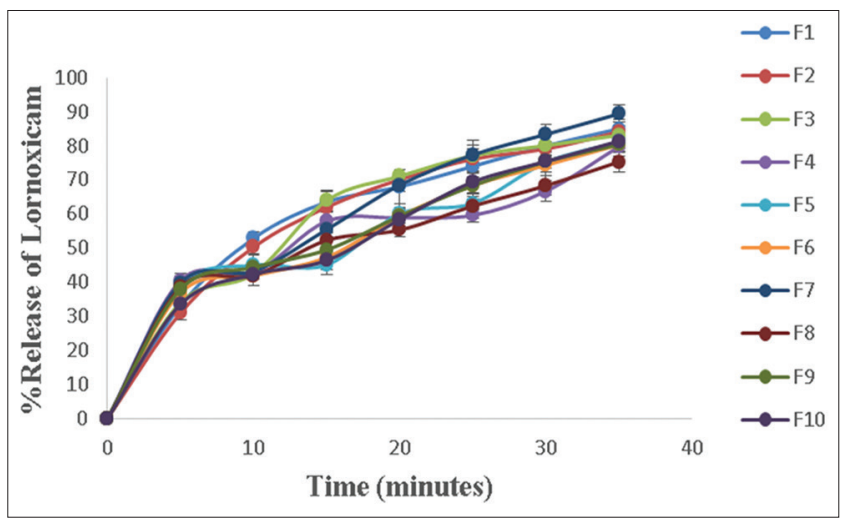

Fig. 2: Lornoxicam release studies from different suppository formulations $(n=3)$

There was a possibility that lornoxicam release will be affected by the presence of aloin. However, the release of lornoxicam was not affected and was consistent with what was previously reported by Landged et al. Landged et al. reported that around $80 \%$ of lornoxicam were released from PEG combination suppositories after 35 min [26] which is consistent with release studies from the combined suppositories prepared.

\section{CONCLUSION}

A combination rectal suppository of lornoxicam and aloin was successfully prepared using different PEG base combinations. When evaluated, all the formulated suppository batches met the USP requirements regarding weight variation, hardness, drug content, friability, disintegration, and melting time. When the in vitro release study was performed, both drugs were released from the suppository. Although all the formulations prepared were successful in terms of general suppository requirements and release, F7 was superior to the other formulations. The highest percentage of drug release for both drugs $(80 \%)$ was from $\mathrm{F} 7$ formula, which is composed of PEG 400 30.88\% (w/w): PEG 4000 46.32\% (w/w). Our current work has proposed a combined rectal suppository of aloin and lornoxicam. The proposed new combination has the potential to be used as a strong analgesic and anti-inflammatory treatment compared to using lornoxicam or aloin alone.

\section{REFERENCES}

1. Kristensen LE, Bliddal H, Christensen R, Karlsson JA, Gülfe A, Saxne T, et al. Is swollen to tender joint count ratio a new and useful clinical marker for biologic drug response in rheumatoid arthritis? Results from a Swedish cohort. Arthritis Care Res (Hoboken) 2014;66:173-9.

2. Brennan-Olsen SL, Cook S, Leech MT, Bowe SJ, Kowal P, Naidoo N, et al. Prevalence of arthritis according to age, sex and socioeconomic status in six low and middle income countries: Analysis of data from the World Health Organization study on global AGEing and adult health (SAGE) Wave 1. BMC Musculoskelet Disord 2017;18:271.

3. Papana A, Meng SJ, Wei YX, Wang W, Ruth M, Page C, et al. Prevalence of rheumatoid arthritis in low-and middle-income countries. Am J Glob Health 2015;5:1-10.

4. Reginster JY. The prevalence and burden of arthritis. Rheumatology (Oxford) 2002;41 Supp 1:3-6.

5. Saag KG, Teng G, Patkar NM, Anuntiyo J, Finney C, Curtis JR, et al. American College of Rheumatology 2008 recommendations for the use of nonbiologic and biologic disease-modifying antirheumatic drugs in rheumatoid arthritis. Arthritis Rheum 2008;59:762-84.

6. Kapoor B, Singh SK, Gulati M, Gupta R, Vaidya Y. Application of liposomes in treatment of rheumatoid arthritis: Quo vadis. ScientificWorldJournal 2014;2014:978351.

7. Macpherson J, Russell S. Side effects of nonsteroidal antiinflammatory small and large intestine in humans. Gastroenterology 1993;104:1832-47.

8. Brune K, Patrignani P. New insights into the use of currently available non-steroidal anti-inflammatory drugs. J Pain Res 2015;8:105-18.

9. Silverstein FE, Faich G, Goldstein JL, Simon LS, Pincus T, Whelton A, et al. Gastrointestinal toxicity with celecoxib vs nonsteroidal anti-inflammatory drugs for osteoarthritis and rheumatoid arthritis: The CLASS study: A randomized controlled trial. Celecoxib Long-term Arthritis Safety Study. JAMA 2000;284:1247-55.

10. Warrington SJ, Debbas NM, Farthing M, Horton M, Johnston A, Thillainayagam A, et al. Lornoxicam, indomethacin and placebo: Comparison of effects on faecal blood loss and upper gastrointestinal endoscopic appearances in healthy men. Postgrad Med J 1990;66:622-6.

11. Byrav DS, Medhi B, Prakash A, Patyar S, Wadhwa S. Lornoxicam: A newer NSAID. Drug Rev 2009;20:27-31.

12. Pushpa K, Mahesh K. An overview on plants with anti-inflammatory potential. Int J Curr Pharm Res 2017;9:1-4.

13. Corrêa GM, Gomes V, Costa DA, Alois D, Martins DE, Takahashi JA, et al. Anti-inflammatory and antimicrobial activities of steroids and triterpenes isolated from aerial parts of Justicia acuminatissima (Acanthaceae). Int J Pharm Pharm Sci 2014;6:75-81.

14. Nanjundaiah SM, Kim HR, Rajaiah R, Yang Y, Tong L, Yu H, et al. Control of autoimmune arthritis by herbal extracts and their bioactive components. Asian J Pharm Sci 2016;11:301-7.

15. Langmead L, Feakins RM, Goldthorpe S, Holt H, Tsironi E, De Silva A, et al. Randomized, double-blind, placebo-controlled trial of oral Aloe vera gel for active ulcerative colitis. Aliment Pharmacol Ther 2004;19:739-47.

16. Rohilkhand MJ, Sai S, Madan J, Sharma AK, Singh R. Fast dissolving tablets of Aloe vera Gel. Trop J Pharm Res 2009;8:63-70.

17. Radha MH, Laxmipriya NP. Evaluation of biological properties and clinical effectiveness of Aloe vera: A systematic review. J Tradit Complement Med 2014;5:21-6

18. Patel K, Patel DK. Medicinal importance, pharmacological activities, and analytical aspects of aloin: A concise report. J Acute Dis 2013;2:262-9

19. Park MY, Kwon HJ, Sung MK. Evaluation of aloin and aloe-emodin as anti-inflammatory agents in aloe by using murine macrophages. Biosci Biotechnol Biochem 2009;73:828-32.

20. Moghimipour E, Dabbagh MA, Zarif F. Characterization and in vitro evaluation of piroxicam suppositories. Asian J Pharm Clin Res 2009;2:92-8

21. British Pharmacopeial Commisssion. British Pharmacopoeia. London: The Stationery Office on Behalf of the Medicines and Healthcare Products Regulatory Agency, MHRA; 2013.

22. Zawar LR, Bhandari GS. Formulation and evaluation of sustained release ondansetron poloxamer based solid suppositories. J Appl Pharm Sci 2012;2:186-90

23. Allen LV. Quality control of suppositories. Suppositories. $1^{\text {st }}$ ed. UK: The Pharmaceutical Press; 2008. p. 139-58.

24. Varshney HM, Chatterjee A. Formulation, evaluation and in vitro release characterisatics of zaltoprofen suppositories. Asian J Pharm Clin Res 2012;5:235-8.

25. Abass H, Kamel R, Abdelbary A. Metronidazole bioadhesive vaginal suppositories: Formulation, in vitro and in vivo evaluation. Int J Pharm Pharm Sci 2012;4:344-53.

26. Tarkase KN, Danve AV. Formulation evaluation and in-vitro drug release characteristics of Aloe vera herbal suppositories. Der Pharm Lett 2015;7:310-6. 
27. Baviskar P, Jaiswal S, Sadique S, Landged A. Formulation and evaluation of lornoxicam suppositories. Pharm Innov J 2013;2:20-8.

28. Tawfeek HM. Lornoxicam suppositories: In-vitro formulation and in-vivo evaluation. Int J Pharm Sci Res 2013;4:4228-35.

29. Ogundipe OD, Oladimeji FA. Quantitative analysis of the effects of drug-base ratio on the physical and release properties of paracetamol suppositories. Pharm Innov J 2017;6:190-6

30. Suryakumari C, Anusha A, Anitha P, Ravindra D. Formulation and evaluation of cow Ghee as a base fast and sustained release chloroquine phosphate suppositories. World J Pharm Pharm Sci 2014;3:1493-509. 